\title{
Physical activity and associated factors among pregnant women in Ethiopia: facility-based cross-sectional study
}

Teklehaimanot Tekle Hailemariam", ${ }^{\text {, }}$ Yosef Sibhatu Gebregiorgis ${ }^{2}$, Berihu Fisseha Gebremeskel', Tsiwaye Gebreyesus Haile ${ }^{1}$ and Theresa Monaco Spitznagle ${ }^{3}$

\begin{abstract}
Background: Regular physical activity (PA) has health benefits, including reducing the risk of complications during pregnancy. In Ethiopia, little is known about PA status and its determinants among pregnant women. The purpose of this study was to assess PA status and associated factors among pregnant women attending antenatal care at public and private health facilities in Mekelle, Ethiopia.

Methods: A facility-based cross-sectional study was conducted. Data was collected from 299 pregnant women using a structured questionnaire. Study participants were selected using a simple random sampling technique. A binary logistic regression was modeled to investigate the statistical significance of independent variables with PA status during pregnancy. Factors associated with PA status were estimated using adjusted odds ratios with 95\% confidence intervals and statistical significance was declared at $p$-value $<0.05$.

Results: $79.3 \%$ of the study participants were classified as sedentary. The age group of 26-35 years (AOR: 2.69, 95\% Cl: 1.07-6.78), attending non-formal education (AOR: 13.50, 95\% Cl: 2.65-68.91), and women who did not work outside the home (AOR: $5.23,95 \% \mathrm{Cl}: 1.34-20.38)$ were significantly associated with a higher risk of sedentary activity status. Pregnant women who were married (AOR: 0.26, 95\% Cl: 0.09-0.73), had two children (AOR: 0.13, 95\% Cl: $0.03-0.59$ ), traveled an hour or more to health facilities (AOR: $0.31,95 \% \mathrm{Cl}: 0.11-0.89$ ) were protected from being sedentary.

Conclusion: Sedentary PA status was highly prevalent during pregnancy. Pregnant women in the age group of 2635 years, with a non-formal education, and women who did not work outside the home had a greater risk of reporting being sedentary. Those who were married, had two children, and traveled an hour or more to health facilities were less likely to be sedentary. Stakeholders (Tigrai regional health bureau, Mekelle University, local NGOs working with pregnant women and societies at large) should give higher emphasis on designing appropriate strategies including educational interventions to overcome barriers to PA during pregnancy.
\end{abstract}

Keywords: Physical activity, Maternal health, Pregnancy, Exercise, Mekelle

\footnotetext{
* Correspondence: tekle525@gmail.com

${ }^{1}$ Department of Physiotherapy, School of Medicine, College of health

sciences, and Ayder comprehensive specialized hospital, Mekelle University,

P.O. Box - 1871, Tigrai, Mekelle, Ethiopia

Full list of author information is available at the end of the article
}

(c) The Author(s). 2020 Open Access This article is distributed under the terms of the Creative Commons Attribution 4.0 International License (http://creativecommons.org/licenses/by/4.0/), which permits unrestricted use, distribution, and reproduction in any medium, provided you give appropriate credit to the original author(s) and the source, provide a link to the Creative Commons license, and indicate if changes were made. The Creative Commons Public Domain Dedication waiver (http://creativecommons.org/publicdomain/zero/1.0/) applies to the data made available in this article, unless otherwise stated. 


\section{Background}

Physical activity (PA) is defined as any bodily movement produced by skeletal muscles that require energy expenditure [1]. According to the American College of Obstetrics and Gynecology (ACOG), pregnant women achieve at least 150 min or more per week of moderate-intensity PA they are labeled as physically active, otherwise, they are classified as sedentary [2]. Reduced PA is rising across many countries in the world with major health implications including increased non-communicable diseases (NCDs) such as cardiovascular disease, diabetes and cancer and their shared common risk factors like raised blood pressure, raised blood sugar and overweight, and it has been identified as a risk factor for $6 \%$ of all deaths, worldwide [3]. In general, a quarter of the world's population in particular women compared to men do not meet the minimal PA recommendations that signifying physically inactive [4].

Pregnancy is a period in women's lives characterized by intense physiological, physical and psychological changes in which maternal systems adapt to accommodate the increasing demands of fetal growth and development $[5,6]$. These adaptational changes can lead to various pregnancy-induced health problems such as low back pain, gestational diabetes mellitus (GDM), hypertension, pre-eclampsia, fetal growth restriction, urinary incontinence, mental disorders, and maternal obesity [6, 7]. Pregnant women who engage in the prescribed PA requirements during their pregnancies reduced the risk of the aforementioned health problems [3, 6-10]. Several studies have also documented other health benefits of increased PA during pregnancy, include decreasing the incidence of preterm birth [5] and cesarean deliveries [8], improved cardiovascular function [9], improvement or maintenance of physical fitness, reduced symptoms of depression [10], and enhanced psychologic well-being [2]. Nevertheless, many women tend to decrease instead of maintain or increase their PA during pregnancy [11-22].

The rates of physical inactivity (women who did not achieve the minimum PA recommendation) during pregnancy range between 64.5 and $91.5 \%$, and tend to be higher in the third trimester of pregnancy [5-8, 23].

Reported factors associated with a higher risk for inactivity or decreased PA during pregnancy across the globe are varied, including older age, low-income, low level of education, poor health status, [15, 24, 25], fear of miscarriage [17], inadequate knowledge [1, 15, 26], lack of supportive environment, [27], physical changes [1, 15], and increased parity [25].

Traditionally it has been thought that, in African and other low-income regions, there is a high physical workload associated with household activities and thus pregnant women who live in low-income regions are more physically active [28]. However, recent studies in Nigeria,
Zambia, and South Africa have demonstrated the opposite perspective, women are now reporting reduced PA during pregnancy in these regions $[25,29,30]$. In addition, in each of these regions in Africa, similar factors associated with reduced PA have been reported during pregnancy. Older age, lower education and income, history of smoking, poor health status, and excess weight gain among African women has been found to be associated with perceived decrease participation in PA [1, 14, 15, 17, 19, 25-27].

In Ethiopia, little is known concerning the PA status and associated factors (maternal weight control and fitness, alleviating pregnancy-related pain and psychological symptoms) among pregnant women. A single study conducted in Jimma Ethiopia by Hjorth et al. [31] revealed that $76.4 \%$ of pregnant women surveyed reported spending most of their time doing sedentary activities, including eating, sitting, sleeping/resting in bed and cooking. However, no other research has been executed on this topic in Ethiopia. Thus, the purpose of this study was to assess PA status and associated factors among pregnant women attending antenatal care at public and private health facilities in Mekelle, Ethiopia.

\section{Methods}

\section{Study design and setting}

A facility-based cross-sectional study was conducted from January 10, 2018, to February 10, 2018, in Mekelle, Ethiopia. Mekelle is a city located around $780 \mathrm{~km}$ north of the Ethiopian capital, Addis Ababa, at an elevation of $2084 \mathrm{~m}$ above sea level, in the region of Tigrai. The Tigrai regional state has five zones. Mekelle city being designated as the regional capital city. Mekelle is administratively divided into seven sub-cities in which the entire Tigrai population obtains their specific healthcare services. Mekelle has three public hospitals, nine health centers, four private hospitals, more than 30 private clinics, and one ortho-physiotherapy center. Of these, 12 public and 7 private health facilities were providing antenatal care services.

Mekelle has a total population of 358,529 of whom 176,986 are females [32]. The Ethiopian Demographic and Health Survey (EDHS 2016) reported a countrywide fertility rate of 4.6, 42, and 33\% employment status for women. However, in Tigrai, this national report revealed a similar fertility rate $4.7 \%$ and a slightly higher, literacy rate $51 \%$, and employment status $37.4 \%$ of women. In addition, in Tigrai, health facility delivery rate is $56.9 \%$ (716 births per 1129 interviewed women) with the same proportion (56.5\%) gave births in public health facilities followed by at home $(41.0 \%)$. Furthermore, $59.3 \%$ of births were delivered by a skilled provider, and $49.6 \%$ of these births were attended by nurse or midwife followed by traditional birth attendants (23.2\%) [33]. 


\section{Study population}

Pregnant women during any trimester of pregnancy who were attending antenatal care during the data collection period at randomly selected public (12) and private health facilities (7).

\section{Inclusion criteria}

Study participants who were having antenatal care during the data collection period in the selected public and private health facilities.

\section{Exclusion criteria}

Pregnant women who presented with medical or obstetric complications and serious psychological conditions that could have an impact on the reliability of data/information were excluded.

\section{Sample size, sampling techniques, and procedures}

The required sample size was determined using a single population proportion formula based on the assumption of a $95 \%$ confidence interval with a margin of error of $5 \%$. A simple random sampling technique was used to select the eight public and private health facilities out of 19 utilized for data collection. These health facilities were chosen because they provide antenatal services and report to the Tigrai Regional Health Bureau (TRHB). According to the Federal Democratic Republic of Ethiopia Ministry of Health; health and health-related indicators in 2016/2017 report indicated that in Tigrai, $125,373(69.5 \%)$ of women had at least four antenatal visits during their last pregnancy, and 118,219 (65.5\%) of births was delivered by skilled attendants [34].

The number recruited from each health facility was determined based on a population-based proportion that was developed considering the TRHB 2009 Ethiopian Fiscal Year (EFY) annual report and recent data reported by the health institutions for the third quarter of the previous year. All eligible pregnant women attending their antenatal care visits at selected health facilities during the study period were randomly approached for inclusion until the total sample size was attained. A total of 305 participants was targeted based on these calculations (Fig. 1).

\section{Data collection instrument and methods}

Data were collected using a structured questionnaire developed from reviewing relevant literature. The questionnaire contains socio-demographic, obstetric and health, physical activity characteristics, and Pregnancy Physical Activity Questionnaire (PPAQ) which was developed by Chasan-Taber et al. [35]. A slight modification was made on PPAQ tool; for instance, two items like "playing with pets, and "mowing the lawn by riding a mower", and by using a walking mower, raking, and gardening" were omitted in the present study's tool due to cultural and feasibility issues in the Ethiopian context.

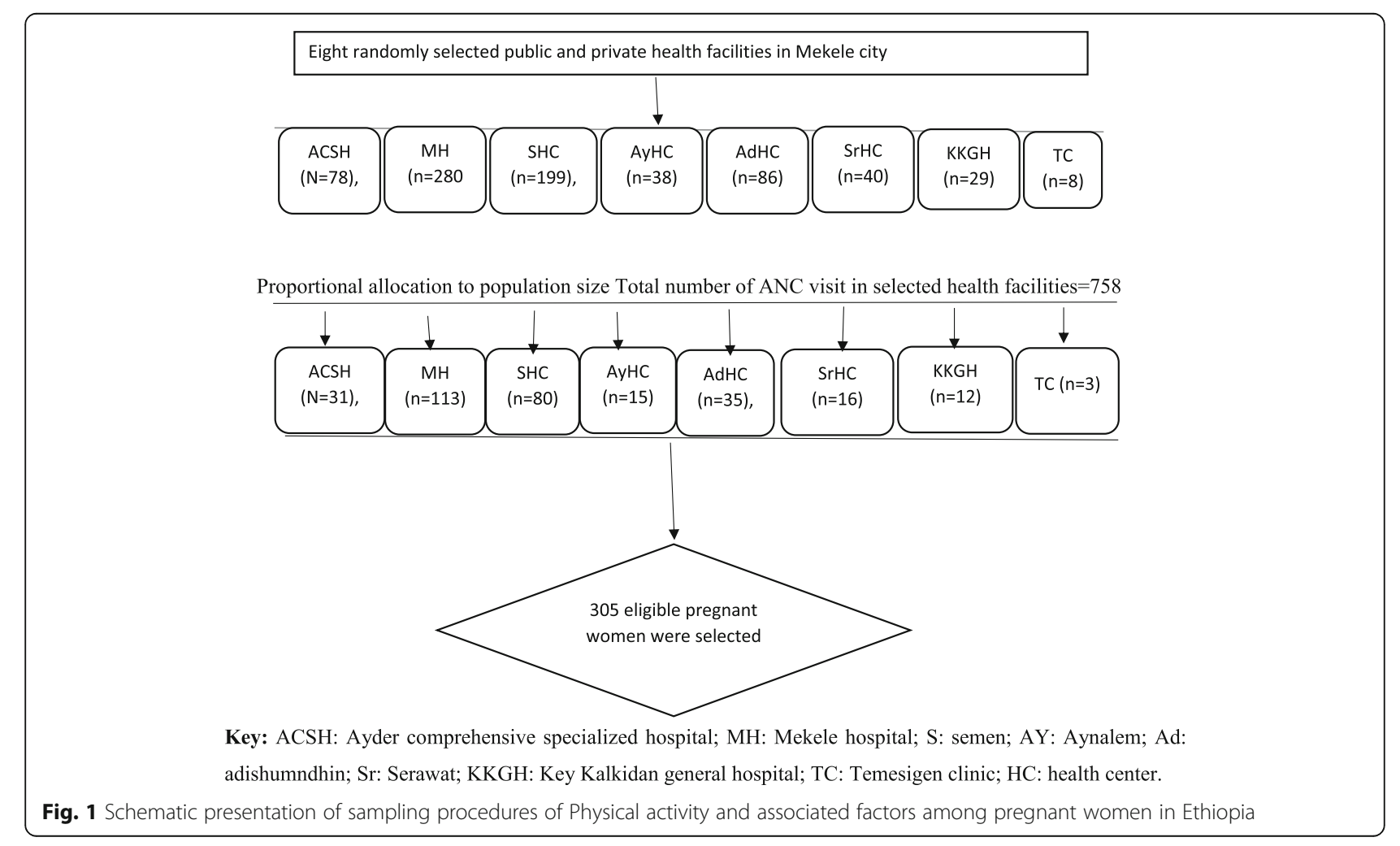


Four experts (one obstetric and gynecologist, two chief physiotherapy specialists and one chief midwifery) with good knowledge of the subject matter of the study's theme and both language versions had contextually constructed the contents of the original and local language versions of the PPAQ.

A questionnaire was translated into Tigrigna which is entirely an official language spoken in the Tigrai region, Ethiopia. This questionnaire was pretested on 5\% (15) of pregnant women who were not part of the study participants from similar health settings and based on pretesting feedback modifications were made to the survey prior to administration.

For each activity, respondents were asked to select the category that best approximates the amount of time spent on that activity per day or week during the current trimester. At the time of recruitment, the women were informed about the purposes and procedures of this study. After highlighting the introduction and receiving oral and written consent, the participants completed the questionnaires for over $15 \mathrm{~min}$ in a quiet place in the clinic.

The PPAQ measures the frequency and duration of activities and gives an intensity value to each activity developed by Chasan-Taber et al. (31). The calculation was total activity $=$ sum of (duration * intensity) for each question. Each activity was classified according to intensity in Metabolic Equivalent Task (MET)-sedentary $(<1.5$ MET), low (1.5 to <3.0 MET), moderate (3.0 to 6.0 MET), and vigorous-intensity (>6.0 MET) - and type-labor, domestic (e.g., caring for a person), and sports/exercise [35].

\section{Data processing and analysis}

After the collection of data, all collected questionnaires were checked for completeness, correctness, and internal consistency to exclude missing or inconsistent data. Data were entered, cleaned and analyzed using IBM SPSS Statistics version 23. Descriptive statistics were computed using frequencies with percentages for categorical variables and median and interquartile range (IQR) for continuous variables. The binary logistic regression model was used to model the association between outcome and independent variables. The final model was assessed for multicollinearity using Variance Inflation Factor (VIF) and goodness of fit using Hosmer and Lemeshow test for independents which make a variable selection decision at each step of the modeling process [36]. Any variable having a significant univariate test with cut-off point p, 0.25 was a candidate for the multivariate analysis [36]. Adjusted odds ratios (AORs) with 95\% confidence intervals (CIs) were estimated. A $p$-value of $<0.05$ was considered statistically significant. During the analysis phase, each categorical variable having five or more cells were not merged in the categorization of variables.

\section{Ethical considerations}

This research was conducted after obtaining ethical clearance from the Health Research Ethics Review Committee (HRERC) of the College of Health Sciences, Mekelle University. The study was conducted with written and oral consent that assures the willingness of each participant to participate in the study. The pregnant women who were unwilling to participate in the study were respected and only those who were willing to participate in the study were recruited. Each participant signed an informed consent form. Confidentiality and privacy of the pregnant woman were also kept protected.

\section{Results}

Overview of the status of physical activity

This study has used complete data collected from 299 pregnant women in the analysis phase; 6 incomplete questionnaires were excluded.

Two hundred and ninety-nine women participated in this study, 79.3\% (237) were classified as sedentary based on results on the adapted PPAQ. Because $95 \%$ of the sample studied attended public antenatal clinics, a comparison across sites, public compared to private clinics was not performed, the relationship of the type of facility to PA status could not be determined. The following provides specific details on the significant associated factors that were related to PA status.

\section{Socio-demographic characteristics of pregnant women}

This study included 299 pregnant women. Nearly half of pregnant women; 148 (49.5\%) were between the ages of 16 to 25 years and 289 (96.7\%) pregnant women were Tigrian. Only $122(40.8 \%)$ had a high school level of education, 281 (94\%) living in the urban area and 265 $(88.6 \%)$ women reported that their religious affiliation was Orthodox Christian. Of the pregnant women who were surveyed, $262(87.6 \%)$ were married and more than half of the study participants, 168 (56.2\%) were women who did not work outside the home. Participants' sociodemographic characteristics of pregnant women are presented in (Table 1).

\section{Obstetric and health characteristics of pregnant women}

Just over half of the women 154 (51.5\%) were in their third trimester, women had a BMI of $210(72.7 \%)$ and $131(43.8 \%)$ of the pregnant women were nulliparous. 284 (95.0\%) were attending antenatal care at a public health facility most of the pregnant women 233 (77.9\%) were spending less than an hour to travel to the health facility, 292 (97.7\%) had a history of feeling healthy before getting pregnant and 178 (59.5\%) had no current symptoms of discomfort. See other corresponding characteristics in (Table 2). 
Table 1 Socio-demographic characteristics of pregnant women attending antenatal care at public and private health facilities in Mekelle, Ethiopia, May $2018(n=299)$

\begin{tabular}{|c|c|}
\hline Variables & Frequency, n (\%) \\
\hline \multicolumn{2}{|l|}{ Age group (years) } \\
\hline $16-25$ & $148(49.5)$ \\
\hline $26-35$ & $136(45.5)$ \\
\hline$\geq 36$ & $15(5.0)$ \\
\hline \multicolumn{2}{|l|}{ Ethnicity } \\
\hline Tigray & $289(96.7)$ \\
\hline Others $^{\mathrm{a}}$ & $10(3.3)$ \\
\hline \multicolumn{2}{|l|}{ Level of education } \\
\hline Unable to read and write & $21(7.0)$ \\
\hline Non-formal education & $22(7.4)$ \\
\hline Primary school (1-8 grades) & $51(17.1)$ \\
\hline High school (9-12 grades) & $122(40.8)$ \\
\hline College/university and above level & $83(27.8)$ \\
\hline \multicolumn{2}{|l|}{ Residence } \\
\hline Rural & $18(6.0)$ \\
\hline Urban & $281(94.0)$ \\
\hline \multicolumn{2}{|l|}{ Religion } \\
\hline Orthodox & $265(88.6)$ \\
\hline Muslim & $30(10.0)$ \\
\hline Others $^{b}$ & $4(1.3)$ \\
\hline \multicolumn{2}{|l|}{ Marital status } \\
\hline Married & $262(87.6)$ \\
\hline Not married & $37(12.4)$ \\
\hline \multicolumn{2}{|l|}{ Occupational (employment) status } \\
\hline Government employee & $41(13.7)$ \\
\hline Private institution/business & $38(13.0$ \\
\hline women who did not work outside the home & $168(56.2)$ \\
\hline Student & $11(3.7)$ \\
\hline Merchant & $37(12.4)$ \\
\hline
\end{tabular}

Others ${ }^{\mathrm{a} A m h a r a, ~ O r o m o ~ a n d ~ G u r a g e ; ~ O t h e r s ~}{ }^{\mathrm{b}}$ Adventist, Catholic and Protestant

\section{Physical activity characteristics of pregnant women}

Of the 299 study pregnant women, 211 (70.6\%) had received advice about PA from a medical professional with the majority of the advice associated with PA being received from a nurse or midwife 88 (29.5\%). Prior to pregnancy, 227 (75.9\%) of the pregnant women reported habitual exercise (the usual practice of any PA) whereas, only $110(48.5 \%)$ of the women reported continuing to exercise during pregnancy. The most common reported reason for not exercising during pregnancy was fear of miscarriage 35 (11.7\%). The common source of information about PA during pregnancy came from medical/ health institutions 145 (48.5\%). Walking was the most
Table 2 Obstetric and health characteristics of pregnant women attending antenatal care at public and private health facilities in Mekelle, Ethiopia, May 2018 ( $n=299)$

\begin{tabular}{|c|c|}
\hline Variables & Frequency, n (\%) \\
\hline \multicolumn{2}{|l|}{ Stage of pregnancy } \\
\hline First trimester $\leq 13$ weeks & $34(11.4)$ \\
\hline Second trimester $[13-24,26]$ weeks & $111(37.1)$ \\
\hline Third trimester $\geq 28$ weeks & $154(51.5)$ \\
\hline \multicolumn{2}{|l|}{ Prenatal visits } \\
\hline Public health facility & $284(95.0)$ \\
\hline Private health facility & $15(5.0)$ \\
\hline \multicolumn{2}{|l|}{ Parity } \\
\hline 0 child & $131(43.8)$ \\
\hline 1 child & $79(26.4)$ \\
\hline 2 children & $47(15.7)$ \\
\hline$>2$ children & $42(14.0)$ \\
\hline \multicolumn{2}{|l|}{ Travel time to a health facility } \\
\hline$<60 \min$ & $233(77.9)$ \\
\hline An hour or more ( $\geq 60 \mathrm{~min})$ & $66(22.1)$ \\
\hline \multicolumn{2}{|l|}{ History of health status } \\
\hline Feel healthy & $292(97.7)$ \\
\hline Sick/ill & $7(2.3)$ \\
\hline \multicolumn{2}{|l|}{ Symptoms of discomfort } \\
\hline Yes & $121(40.5)$ \\
\hline No & $178(59.5)$ \\
\hline \multicolumn{2}{|l|}{ Pre-gravid work status } \\
\hline Yes & $149(49.8)$ \\
\hline No & $150(50.2)$ \\
\hline \multicolumn{2}{|l|}{ BMl } \\
\hline Underweight: $<18.5 \mathrm{~kg} / \mathrm{m}^{2}$ & $31(10.7)$ \\
\hline Normal: $18.5-24.99 \mathrm{~kg} / \mathrm{m}^{2}$ & $210(72.7)$ \\
\hline Overweight: $25-29.99 \mathrm{~kg} / \mathrm{m}^{2}$ & $41(14.2)$ \\
\hline Obesity: $\geq 30$ kg/m² & $7(2.4)$ \\
\hline
\end{tabular}

commonly reported mode of exercise 258 (86.3\%). The physical activity characteristics of pregnant women are presented in (Table 3).

\section{Physical activities across trimesters}

This study revealed that pregnant women had more or less similar median total energy expenditure across the first, second and third trimesters ( 3.23 vs 3.35 vs 3.23 MET h/week) respectively. The median energy expenditures on light activities during the three trimesters were 1.61 vs 1.78 vs 1.80 respectively. The amount of energy spent on household activities was also found across first, second and third trimesters (1.33 vs 1.59 vs 1.83 MET h/week) respectively. Physical activities across trimesters are presented in (Table 4). 
Table 3 Physical activity characteristics of pregnant women attending antenatal care at public and private health facilities in Mekelle, Ethiopia, May $2018(n=299)$

Variables

Yes

Frequency $\mathrm{n}(\%)$

$211(70.6)$

$88(29.4)$

Exercise advised by

Medical doctor

$50(16.7)$

Nurse/midwives

$88(29.5)$

Health officer

$1(0.3)$

Health extension package

$72(24.1)$

Method of education on exercise advice

Individual

$181(60.5)$

In a group of other pregnant women

$29(9.8)$

Brochure

$1(0.3)$

A habit of exercise before pregnancy

Yes

$227(75.9)$

No

$72(24.1)$

A habit of exercise while pregnant

I continued doing exercises

$110(36.8)$

I stopped the exercises

$45(15.1)$

$72(24.1)$

I continued to exercise but slowed down

Reasons stopped exercise activities during pregnancy

Fear of miscarriage

$35(11.7)$

Too Tired

$5(1.7)$

Having no time

$3(1.1)$

Discomfort

Dislikes exercise

Comfortable environment

Yes

$231(77.3)$

No

$68(22.7)$

Reasons for lack of comfortable environment

Lack of a safe and secure environment

Cold temperature

Lack of accessibility to do exercise

Others

$5(1.7)$

Self-evaluation of physical activity level prior to pregnancy

Low

$40(13.4)$

Moderate

$237(79.3)$

High

$22(7.4)$

Self-evaluation of current physical activity

Less active

$123(41.1)$

Increased activity

$29(9.7)$

No change

147 (49.2)

Habitual (usual) exercises with husband or partner

Table 3 Physical activity characteristics of pregnant women attending antenatal care at public and private health facilities in Mekelle, Ethiopia, May $2018(n=299)$ (Continued)

\begin{tabular}{cl}
\hline Variables & Frequency $\mathrm{n}(\%)$ \\
\hline Yes & $193(64.8)$ \\
No & $106(35.2)$
\end{tabular}

Sources of information about exercise ${ }^{a}$

Books and newspapers 13 (4.3)

Friends or relatives $\quad 69(23.1)$

Multi-Media $89(29.8)$

Medical/Health institutions 145 (48.5)

Public announcement 6 (2.0)

The person who encouraged you to exercise ${ }^{a}$

Husband or partner $\quad 54$ (18.1)

Medical staff $36(12.0)$

Other family members or friends $\quad 6(2.0)$

Herself

$214(71.6)$

Preferred mode of exercise ${ }^{a}$

Walking slowly

$258(86.3)$

Dancing

$17(5.7)$

Prenatal exercise class $14(4.7)$

Swimming $2(0.7)$

Walking quickly 11 (3.7)

Climb hill $2(0.7)$

Running slowly 8 (2.7)

Running quickly $1(0.3)$

${ }^{a}$ could choose more than one

\section{Bivariate and multivariate analysis of factors associated} with PA status among pregnant women

The bivariate analysis of the present study revealed that twelve independent variables were a candidate for the final model analysis with cut-off points $(p<0.25)$. These variables are; age group, level of education, marital status, occupational status, stage of pregnancy, parity, travel time to a health facility, symptoms of discomfort, exercises advice from a medical professional, habit of exercise while pregnant, self-evaluation of PA level prior to pregnancy and self-evaluation of current physical activity.

Multivariate analysis revealed that several independent predictors were significantly associated with PA status; Pregnant women in the age group of 26-35 years were 2.69 times more likely to be sedentary (AOR: 2.69, 95\% CI: 1.07-6.78) compared with those in the age group of 16-25 years. Pregnant women who had a non-formal education were 13.50 times more likely to be sedentary (AOR: 13.50, 95\% CI: 2.65-68.91) compared to those who had graduated from college/university and above level. However, pregnant women who were married were less likely to be sedentary (27\%) compared to those who 
Table 4 Physical activities across trimesters attending antenatal care at public and private health facilities in Mekelle, Ethiopia, May $2018(n=299)$

\begin{tabular}{|c|c|c|c|}
\hline Physical activities (MET-h/week) & 1ST trimester $\leq 13$ weeks $(n=34)$ & $\begin{array}{l}\text { 2nd trimester }(14-27) \\
\text { weeks }(n=111)\end{array}$ & $\begin{array}{l}\text { 3rd Third trimester } \geq 28 \\
\text { weeks }(n=154)\end{array}$ \\
\hline \multicolumn{4}{|l|}{ Median (IQR) } \\
\hline Total energy expenditure per week & $3.23(2.36)$ & $3.35(2.53)$ & $3.23(2.17)$ \\
\hline \multicolumn{4}{|l|}{ By activity intensity $(n=299)$} \\
\hline Sedentary & $0.62(0.66)$ & $0.58(0.88)$ & $0.51(0.63)$ \\
\hline Light & $1.61(1.19)$ & $1.78(1.06)$ & $1.80(1.31)$ \\
\hline Moderate & $0.66(1.58)$ & $0.77(1.16)$ & $0.59(1.18)$ \\
\hline Vigorous & $0.00(0.00)$ & $0.00(0.00)$ & $0.00(0.00)$ \\
\hline \multicolumn{4}{|l|}{ By type of activity } \\
\hline Household/caregiving & $1.33(2.02)$ & $1.59(1.44)$ & $1.83(1.52)$ \\
\hline Occupational $(n=130)^{\mathrm{a}}$ & $1.41(1.8)$ & $1.48(1.07)$ & $1.44(1.03)$ \\
\hline Sports/exercise & $0.10(0.15)$ & $0.07(0.1)$ & $0.09(0.13)$ \\
\hline \multicolumn{4}{|l|}{ n (\%) } \\
\hline Meet the guideline, $\mathrm{n}(\%)$ & $2(5.9)$ & $12(10.8)$ & $11(7.1)$ \\
\hline
\end{tabular}

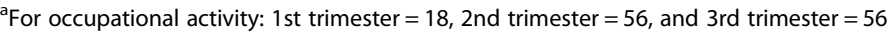

were not married (91\%) (AOR: 0.26, 95\% CI: 0.09-0.73). Pregnant women who did not work outside the home were 5.23 times more likely to be sedentary (AOR: 5.23 , 95\% CI: 1.34-20.38) compared to those who were governmentally employed. Pregnant women who had two children were less likely to be sedentary compared to those who had no child regardless of employment status (AOR: 0.13, 95\% CI: 0.03-0.59). Pregnant women who traveled an hour or more to arrive at a health facility were less likely to be sedentary compared to those who traveled less than an hour (AOR: 0.31, 95\% CI: 0.110.89 ). Women who reported that they exercised regularly during pregnancy but slowed down their overall activity were 2.28 times more likely to be sedentary (AOR: 2.28, 95\% CI: 1.03-5.04) compared to those who were continued to exercise while pregnant and maintained their pre-pregnancy activity status. The detailed analysis of factors associated with PA status among pregnant women is presented in (Table 5).

\section{Discussion}

The purpose of this study was to assess PA status and associated factors among pregnant women attending antenatal care at public and private health facilities in Mekelle, Ethiopia. Sedentary PA status was highly prevalent among pregnant women living in Mekelle and the Tigrai region of Ethiopia. Associated factors among pregnant women who had sedentary PA status were married, did not work outside the home and selfreported decreased travel time to the health facility. Associated factors commonly found in pregnant women with active PA status were in the age group (26-35 years old), had 2 children and a non-formal educational level.
The findings in our study are consistent with studies conducted in Jimma, Ethiopia (76.4\%) [31] and Chili (83\%) [22], both studies included participants from similar socioeconomic and educational levels. In contrast, the reported sedentary PA status is higher than findings that have been documented in higher socioeconomic settings, Denmark (6 to 29\%) [13], in South Africa 30.8\% [30], and 44\% [27] and Nigeria 49.0\% [25]. Our finding indicates that women in our population that have higher socioeconomic status and education are less active during pregnancy compared with pregnant women living in developed countries. Another possible explanation could be due to an epidemiological and nutritional transition that has occurred in sub-Saharan African countries, including Ethiopia, where lifestyle and behavioral changes, have taken place as a product of both modernization and urbanization that promote physical inactivity, increased adult weight gain, and risk of developing cardiovascular disease [37].

Our study also revealed that the energy expenditure among pregnant women across first, second and third trimesters was significantly low (1.33 vs 1.59 vs 1.83 measured by MET-h.wk-1) respectively; where, most of the energy was expended on household and caregiving activities. This low energy expenditure is comparable to a similar study conducted in Jimma, Ethiopia [31]. However, it was significantly lower than the studies done in Portugal (115.085 vs 97.530 vs 96.509 (MET.h.wk-1)) [20] and Nigeria (75.9 MET-h.week-1) [25]. One possible explanation for this observation is more than half (51.5\%) of pregnant women in our cohort were in their third trimester at the time of the data collection period. The third trimester is a period when pregnant women 
Table 5 Bivariate and multivariate analysis of factors associated with physical activity status among pregnant women attending antenatal care at public and private health facilities in Mekelle city, Tigray, Ethiopia, $2018(n=299)$

\begin{tabular}{|c|c|c|c|c|c|}
\hline Variables & Sedentary (237) n (\%) & Active (62) n (\%) & COR $(95 \% \mathrm{Cl})$ & AOR $(95 \% \mathrm{Cl})$ & P-Value \\
\hline \multicolumn{6}{|l|}{ Age group (years) } \\
\hline $16-25$ & $121(40.5)$ & $27(9)$ & (ref) & (ref) & \\
\hline $26-35$ & $106(35.5)$ & $30(10)$ & $1.27(0.71,2.27)$ & $2.69(1.07,6.78)$ & $0.036^{*}$ \\
\hline$>=36$ & $10(3.3)$ & $5(1.7)$ & $2.24(0.71,7.09)$ & $6.66(0.93,7.98)$ & 0.060 \\
\hline \multicolumn{6}{|l|}{ Level of education } \\
\hline Unable to read and write & $17(5.7)$ & $4(1.3)$ & $1.27(0.37,4.38)$ & $2.08(0.49,8.87)$ & 0.324 \\
\hline Non-formal education & $11(3.7)$ & $11(3.7)$ & $5.39(1.93,14.99)$ & $13.5(2.65,68.91)$ & $0.002^{* *}$ \\
\hline Primary school (1-8 grades) & $41(13.7)$ & $10(3.3)$ & $1.31(0.53,3.26)$ & $1.73(0.53,5.64)$ & 0.366 \\
\hline High school (9-12 grades) & $98(32.8)$ & $24(8)$ & $1.32(0.63,2.77)$ & $2.02(0.78,5.23)$ & 0.146 \\
\hline College /university and above level & $70(23.4)$ & $13(4.4)$ & (ref) & (ref) & \\
\hline \multicolumn{6}{|l|}{ Marital status } \\
\hline Married & $211(70.6)$ & $51(17)$ & $0.57(0.27,1.23)$ & $0.26(0.09,0.73)$ & $0.011^{* *}$ \\
\hline Not married & $26(8.7)$ & $11(3.7)$ & (ref) & (ref) & \\
\hline \multicolumn{6}{|l|}{ Occupational (employment) status } \\
\hline Government employee & $37(12.4)$ & $4(1.3)$ & (ref) & (ref) & \\
\hline Private business & $33(11)$ & $9(3.1)$ & $2.39(0.66,8.69)$ & $3.32(0.68,16.16)$ & 0.137 \\
\hline women who did not work outside home & $124(41.5)$ & $44(14.7)$ & $3.30(1.12,9.79)$ & $5.23(1.34,20.38)$ & $0.017^{*}$ \\
\hline Student & $10(3.4)$ & $1(0.3)$ & $0.93(0.09,9.23)$ & $0.95(0.07,12.27)$ & 0.966 \\
\hline Merchant & $33(11)$ & $4(1.3)$ & $1.12(0.26,4.84)$ & $2.06(0.37,11.53)$ & 0.409 \\
\hline \multicolumn{6}{|l|}{ Stage of pregnancy } \\
\hline First trimester $\leq 13$ weeks & $30(10)$ & $4(1.3)$ & (ref) & (ref) & \\
\hline Second trimester (14-27) weeks & $92(30.8)$ & $19(6.4)$ & $1.55(0.49,4.91)$ & $1.52(0.34,6.74)$ & 0.582 \\
\hline Third trimester $\geq 28$ weeks & $115(38.5)$ & $39(13.0)$ & $2.54(0.84,7.68)$ & $2.04(0.49,8.29)$ & 0.322 \\
\hline \multicolumn{6}{|l|}{ Parity } \\
\hline 0 child & $102(34.1)$ & $29(9.7)$ & (ref) & (ref) & \\
\hline 1 child & $65(21.8)$ & $14(4.7)$ & $0.76(0.37,1.54)$ & $0.69(0.29,1.69)$ & 0.429 \\
\hline 2 children & $40(13.4)$ & $7(2.3)$ & $0.62(0.25,1.52)$ & $0.13(0.03,0.59)$ & $0.008^{* *}$ \\
\hline$>2$ children & $30(10.0)$ & $12(4.0)$ & $1.41(0.64,3.09)$ & $0.56(0.13,2.38)$ & 0.435 \\
\hline \multicolumn{6}{|l|}{ Travel time to a health facility } \\
\hline$<60 \min$ & $179(59.9)$ & $54(18.0)$ & (ref) & (ref) & \\
\hline$(\geq 60 \mathrm{~min})$ & $58(19.4)$ & $8(2.7)$ & $0.46(0.21,1.02)$ & $0.31(0.11,0.89)$ & $0.030^{*}$ \\
\hline \multicolumn{6}{|l|}{ Symptoms of discomfort } \\
\hline Yes & $103(34.5)$ & $18(6.0)$ & $1.88(1.03,3.44)$ & $1.74(0.77,3.95)$ & 0.186 \\
\hline No & $134(44.8)$ & $44(14.7)$ & (ref) & (ref) & \\
\hline \multicolumn{6}{|l|}{ Exercise advices from a medical professional } \\
\hline Yes & $163(54.5)$ & $48(16)$ & $0.64(0.33,1.24)$ & $0.60(0.24,1.52)$ & 0.281 \\
\hline No & $74(24.8)$ & $14(4.7)$ & (ref) & (ref) & \\
\hline \multicolumn{6}{|l|}{ A habit of exercise during pregnant } \\
\hline I continued doing exercises & $91(30.4)$ & $19(6.3)$ & (ref) & (ref) & \\
\hline I stopped the exercises & $37(12.4)$ & $7(2.3)$ & $0.91(0.35,2.34)$ & $0.97(0.35,2.70)$ & 0.960 \\
\hline I continued to exercise but slowed down & $51(17.1)$ & $23(7.7)$ & $2.20(1.09,4.43)$ & $2.28(1.03,5.04)$ & $0.041^{*}$ \\
\hline \multicolumn{6}{|l|}{ Self-evaluation of PA level prior to pregnancy } \\
\hline Low & $36(12.1)$ & $4(1.3)$ & $0.50(0.11,2.23)$ & $0.37(0.05,2.60)$ & 0.319 \\
\hline
\end{tabular}


Table 5 Bivariate and multivariate analysis of factors associated with physical activity status among pregnant women attending antenatal care at public and private health facilities in Mekelle city, Tigray, Ethiopia, $2018(n=299)$ (Continued)

\begin{tabular}{|c|c|c|c|c|c|}
\hline Variables & Sedentary (237) n (\%) & Active (62) n (\%) & COR $(95 \% \mathrm{Cl})$ & AOR (95\% Cl) & $P$-Value \\
\hline Moderate & $183(61.2)$ & $54(18.1)$ & $1.33(0.43,4.09)$ & $0.82(0.19,3.44)$ & 0.785 \\
\hline High & $18(6.0)$ & $4(1.3)$ & (ref) & (ref) & \\
\hline \multicolumn{6}{|c|}{ Self-evaluation of PA changes during pregnancy } \\
\hline Less active & $96(32.1)$ & $27(9.0)$ & $0.97(0.55,1.73)$ & $1.05(0.45,2.46)$ & 0.918 \\
\hline Increased activity & $27(9.0)$ & $2(0.7)$ & $0.26(0.06,1.13)$ & $0.37(0.07,2.04)$ & 0.254 \\
\hline No change & $114(38.2)$ & $33(11.0)$ & (ref) & (ref) & \\
\hline
\end{tabular}

usually go on maternity leave which may make them spend more time at home than at work. Another possible reason is more than half $(56.2 \%)$ of the pregnant women were women who did not work outside the home thus, possibly spending more time on household activities rather than work activities, exercise or sports activity.

Of the study participants, only $25(8.4 \%)$ of the pregnant women met the international recommended guideline for PA ( $\geq 150$ min moderate-intensity exercise per week) during pregnancy. This finding is significantly lower compared to similar studies conducted in China (11.1\%) [17], Ireland (21.5\%) [16] and USA (22.9, and 94.5\%) [11, 38]. The wide range of differences among those studies could be due to several issues. As an example, Smith et al. in the USA [38] reported that women had a higher level of awareness, economic status, better motivation and fewer perceived barriers to PA. However, our reported PA was higher compared with a similar study conducted with pregnant women in Jimma, Ethiopia (2.8\%) [31].

The present study showed that pregnant women in the age group of 26-35 years were 2.69 times more likely to have sedentary PA status compared to those who were in the age group of $16-25$ years. This finding is similar to a study conducted by USA National Health and Nutrition Examination Survey in which the young age group, 16-25 years were less likely to be classified as sedentary PA [12]. In a prospective cohort of Britain women, younger women were less likely to decrease their PA levels during pregnancy [14]. A possible reason for this similarity could be because of pregnant women of younger ages in Tigrai, were more actively engaged in different household and occupational activities during pregnancy compared to older women. In Ethiopia, religious belief and culture have an impact on social values. Specifically, it is common to find within a single household that younger household members would be expected to manage any household or occupational activities as a sign of respect for older household members.

This study revealed that pregnant women who had a non-formal education were 13.50 times more likely to have a sedentary PA compared to pregnant women with higher educational levels (graduated College/university and above). This finding is consistent with a similar study conducted in Southeastern Brazil in which the pregnant women who had higher educational levels were more active compared to pregnant women with lower educational levels [18]. However, this study finding is not consistent with a prospective cohort conducted, in Britain, i.e., women with higher educational levels were more likely to decrease their activity levels during pregnancy [14]. In Brazil, this could be related to the possibility that pregnant women with higher educational levels could have more access to knowledge about the benefits of PA whereas, in Britain, those who were highly educated women could have done less household- or occupation-related activities during their pregnancy, and were more likely to spend time on leisure-time PA [14].

This study observed that pregnant women who were married were less likely to be sedentary compared to those who were not married. This finding is consistent with studies conducted in South African, i.e., being married was positively associated with PA [6] and in Britain cohort pregnant women in which women who were married were more active compared to those who were not married [14].

This study also showed that pregnant women who had two children were less likely to be sedentary compared to those who had no child. This study is consistent with studies conducted in southeastern of Brazil in which pregnant women who had two or more children were significantly associated with the increased PA [18] and in Nigeria, i.e., an increasing number of children have increased the probability of being physically active at a moderate level [25]. The relation between an increasing number of children and the possibility of higher PA could be; because pregnant women with more children were a likely higher level of activity required for mothering to be more active compared to those who had no children [25].

This study revealed that pregnant women who traveled an hour or more to arrive at a health facility were less likely to be sedentary compared to those who traveled less than an hour. The possible explanation could be; $86.3 \%$ of pregnant women were performing walking as their primary mode of PA. Thus, those who were 
traveling long distances may have also had chosen walking on foot. Similarly, studies conducted in the USA [11], Britain [23], Portugal [29], Brazil [30], Zambia [14, 18], South Africa [6, 20] showed that walking was the most commonly reported type of PA (29 to $82.2 \%$ ), during pregnancy. The current study also observed that pregnant women who were continued to walk but slowed down (walked less than the usual) were 2.28 times more likely to experience sedentary PA compared to those who continued exercising while pregnant. This finding could possibly be reflective of the concerns that pregnant women have about the safety of exercise causing anxiety, fear of falling or miscarriage as a deterrent to activity.

\section{Limitations of this study}

There were some limitations to the present study. First, the study's findings rely on self-reported rather than objective measurements; hence, there may be a bias in the reported results. Second, data from this cross-sectional study did not illustrate exercise conditions (patterns) throughout pregnancy only at one point in time for any one participant. Finally, there was not enough data from a private institution to determine if there is a difference based on the location of public versus private. Future research should include objective methods for assessing activity ie: use of a pedometer or accelerometer as well as, include a process where data collection is done throughout the pregnancy.

\section{Conclusion}

Self-reported sedentary PA status was highly prevalent. Pregnant women in the age group of 26-35 years, attending non-formal education, and women did not work outside the home were positively associated with a higher risk of being sedentary; however, those who married, had two children, and traveled to health facilities in less than an hour were negatively associated with the PA status. It would be better to recommend that pregnancy care providers educate women about the benefits of exercise during pregnancy and that they should continue where possible to be physically active. The partners or family members should be work together in increasing the PA of pregnant women especially experienced women who did not work outside the home with a history of sedentary PA status. More effort is needed among health professionals who interact with pregnant women to remain aware of the importance of exercise promotion.

Policymakers and other stakeholders (Tigrai regional health bureau, Mekelle University, local NGOs working with pregnant women and societies at large) should encourage PA interventions during antenatal care and target family members to improve the health benefits of pregnant women. They should also consider providing PA guidelines combined with education on the benefits of PA for pregnant women. Furthermore, a longitudinal follow-up (interventional) study on the effect of PA during pregnancy with health outcomes for both mothers and offspring is recommended.

\begin{abstract}
Abbreviations
ACOG: American College of Obstetricians and Gynecologists; AEE: Activity Energy Expenditure; AOR: Adjusted Odds Ratio; B.Sc.: Bachelor of Science; BMI: Body Mass Index; CHS: College of Health Sciences; Cl: Confidence Interval; COR: Crude Odds Ratio; EDHS: Ethiopian Demographic and Health Survey; GDM: Gestational Diabetes Mellitus; KG: Kilo Gram; KJ: Kilo Joule; MET: Metabolic Equivalent Task; MET.h.wk-1: Metabolic Equivalent Task hour per week; MU: Mekele University; NGO: Non-Governmental Organization; PA: Physical Activity; PAL: Physical Activity Level; PPAQ: Pregnant Physical Activity Questionnaire; TRHB: Tigrai Regional Health Bureau; U.S.A: United States of America
\end{abstract}

\section{Acknowledgments}

We would like to acknowledge all study participants, data collectors, supervisors, and Mekelle University who supported this project. In addition, we would also like to thank the Worldwide Fistula Fund for supporting the Masters of Physical Therapy educational program at Mekelle University. Because of the generosity of all mentioned, culturally specific knowledge about the activity status of pregnant women in Ethiopia has grown.

\section{Authors' contributions}

TTH wrote the proposal, participated in the data collection, in the statistical analysis, interpretation, and writing of the manuscript. YSG, BFG, \&TGH, participated in data analysis and writing the methodology section. THH and TMS drafted the initial manuscript. TTH, YSG, BFG, TGH, and TMS contributed to the critical inputs for data analysis and interpretation of results, critically revised the manuscript and made substantial contributions to the final draft. All authors read and approved the final manuscript. TMS provided the final English language edits.

\section{Funding}

Not applicable.

\section{Availability of data and materials}

All data which are relevant to this study such as analysis and conclusions were made are available and supplementary data will be offered upon based on a request.

\section{Ethics approval and consent to participate}

This research was conducted after obtaining ethical clearance from the Health Research Ethics Review Committee (HRERC) of the College of Health Sciences, Mekelle University. Written informed consent was obtained before data collection from each study participants to assure the willingness of each participant to participate in the study after explaining the objective of the study. Confidentiality and privacy of the study participant were also kept protected. Any study participants were informed of the right to withdraw their participation at any time during the interview.

\section{Consent for publication}

Not applicable.

\section{Competing interests}

The authors declare that they have no competing interests, with the exception that collaborative travel costs from the USA to Ethiopia has been supported by the Worldwide Fistula Fund.

\section{Author details}

${ }^{1}$ Department of Physiotherapy, School of Medicine, College of health sciences, and Ayder comprehensive specialized hospital, Mekelle University, P.O. Box - 1871, Tigrai, Mekelle, Ethiopia. ${ }^{2}$ Department of Epidemiology, School of Public health, College of health sciences, Mekelle University, P.O. Box - 1871, Tigrai, Mekelle, Ethiopia. ${ }^{3}$ School of Medicine, Program in Physical Therapy, Washington University, St Louis, MO, USA. 
Received: 19 June 2019 Accepted: 29 January 2020

Published online: 10 February 2020

\section{References}

1. www.who.int/dietphysicalactivity/strategy/eb11344/strategy_english_web. pdf. No Title.

2. Obstetricians AC. Of, gynecologists. Physical activity and exercise during pregnancy and the postpartum period. Committee opinion no. 650. Obstet Gynecol. 2015;126(6):e135-42.

3. Https://www.who.int/diet physical activity/global-PA-recs-2010. No Title.

4. Sallis JF, Bull F, Guthold R, Heath GW, Inoue S, Kelly P, et al. Physical Activity 2016 : Progress and Challenges Progress in physical activity over the Olympic quadrennium; 2016. p. 6736. (July)

5. da Silva SG, Ricardo LI, Evenson KR, Hallal PC. Leisure-time physical activity in pregnancy and maternal-child health: a systematic review and metaanalysis of randomized controlled trials and cohort studies. Sports Med. 2017:47(2):295-317.

6. Watson ED, Van Poppel MNM, Jones RA, Norris SA, Micklesfield LK. Are south African mothers moving? Patterns and correlates of physical activity and sedentary behavior in pregnant black south African women. J Phys Act Health. 2017;14(5):329-35.

7. De Haas S, Ghossein-Doha C, Van Kuijk SMJ, Van Drongelen J, Spaanderman MEA. Physiological adaptation of maternal plasma volume during pregnancy: a systematic review and meta-analysis. Ultrasound Obstet Gynecol. 2017:49(2):177-87.

8. Owe KM, Nystad W, Stigum H, Vangen S, Bø K. Exercise during pregnancy and risk of cesarean delivery in nulliparous women: a large populationbased cohort study. Am J Obstet Gynecol. 2016;215(6):791. e1-791. e13.

9. Stutzman SS, Brown CA, Hains SM, Godwin M, Smith GN, Parlow JL, et al. The effects of exercise conditioning in normal and overweight pregnant women on blood pressure and heart rate variability. Biol Res Nurs. 2010; 12(2):137-48.

10. Robledo-Colonia AF, Sandoval-Restrepo N, Mosquera-Valderrama YF, Escobar-Hurtado C, Ramirez-Velez R. Aerobic exercise training during pregnancy reduces depressive symptoms in nulliparous women: a randomized trial. J Physiother. 2012;58(1):9-15.

11. Evenson KR, Wen F. National trends in self-reported physical activity and sedentary behaviors among pregnant women: NHANES 1999-2006. Prev Med (Baltim). 2010;50(3):123-8.

12. Evenson KR, Wen F. Prevalence and correlates of objectively measured physical activity and sedentary behavior among US pregnant women. Prev Med (Baltim). 2011;53(1-2):39-43.

13. Hegaard HK, Damm P, Hedegaard M, Henriksen TB, Ottesen B, Dykes A-K, et al. Sports and leisure-time physical activity during pregnancy in nulliparous women. Matern Child Health J. 2011;15(6):806-13.

14. Liu J, Blair SN, Teng Y, Ness AR, Lawlor DA, Riddoch C. Physical activity during pregnancy in a prospective cohort of British women: results from the Avon longitudinal study of parents and children. Eur J Epidemiol. 2011; 26(3):237-47 2010/12/30 Available from: https://www.ncbi.nlm.nih.gov/ pubmed/21191632

15. Merkx A, Ausems M, de Vries R, Nieuwenhuijze MJ. Factors affecting perceived change in physical activity in pregnancy. Midwifery. 2017:51:16-23.

16. Walsh JM, McGowan C, Byrne J, McAuliffe FM. Prevalence of physical activity among healthy pregnant women in Ireland. Int J Gynecol Obstet. 2011; 114(2):154-5.

17. Zhang $Y$, Dong S, Zuo J, Hu X, Zhang H, Zhao $Y$. The physical activity level of urban pregnant women in Tianjin, China: a cross-sectional study. PLoS One. 2014;9(10):e109624.

18. Nascimento SL, Surita FG, Godoy AC, Kasawara KT, Morais SS. Physical Activity Patterns and Factors Related to Exercise during Pregnancy: A CrossSectional Study. PLoS One. 2015;10(6):e0128953.

19. Coll C, Domingues M, Santos I, Matijasevich A, Horta BL, Hallal PC. Changes in leisure-time physical activity from the Prepregnancy to the postpartum period: 2004 Pelotas (Brazil) birth cohort study. J Phys Act Health. 2016;13(4): 361-5.

20. Santos PC, Abreu S, Moreira C, Santos R, Ferreira M, Alves O, et al. Physical activity patterns during pregnancy in a sample of Portuguese women: a longitudinal prospective study. Iran Red Crescent Med J. 2016;18(3):e22455 Available from: https://www.ncbi.nlm.nih.gov/pubmed/27247788.

21. Santos PC, Abreu S, Moreira C, Lopes D, Santos R, Alves $O$, et al. Impact of compliance with different guidelines on physical activity during pregnancy and perceived barriers to leisure physical activity. J Sports Sci. 2014;32(14): 1398-408.

22. Leppe J, Besomi MM, Olsen CC, Mena IMJ, Roa AS. Nivel de actividad física según GPAQ en mujeres embarazadas y postparto que asisten a un centro de salud familiar. Rev Chil Obstet Ginecol. 2013;78:425-31 Available from: https://scielo.conicyt.cl/scielo.php?script=sci_arttext\&pid=S0717-75262013 $000600004 \& \mathrm{nrm}=\mathrm{iso}$

23. de VN CC, Domingues MR, Hallal PC, da Silva ICM, Bassani DG, Matijasevich $A$, et al. Changes in leisure-time physical activity among Brazilian pregnant women: comparison between two birth cohort studies (2004-2015). BMC Public Health. 2017:17(1):119.

24. Gaston A, Cramp A. Exercise during pregnancy : A review of patterns and determinants. J Sci Med Sport. 2011;14(4):299-305.

25. Adeniyi AF, Ogwumike OO. Physical activity and energy expenditure: findings from the Ibadan pregnant Women's survey. Afr J Reprod Health. 2014;18(2):117-26.

26. Mbada CE, Adebayo OE, Adeyemi AB, Arije OO, Dada OO, Akinwande OA, et al. Knowledge and attitude of Nigerian pregnant women towards antenatal exercise: a cross-sectional survey. ISRN Obstet Gynecol. 2014;2014 260539.

27. Muzigaba M, Kolbe-Alexander TL, Wong F. The perceived role and influencers of physical activity among pregnant women from low socioeconomic status communities in South Africa. J Phys Act Health. 2014; 11(7):1276-83.

28. Roberts SB, Paul AA, Cole TJ, Whitehead RG. Seasonal changes in activity, birth weight and lactational in rural Gambian women. Trans R Soc Trop Med Hyg. 1982;76:668.

29. Nkhata L, Nkandu E, Shula H. Exercise Practice Among Women Attending Antenatal Care at the University Teaching Hospital in Lusaka, Zambia, vol. 3; 2015. p. 361-5.

30. Brunette EL, Kotze J, Wood PS, Du Toit P, Grant CC. An epidemiological study of physical activity patterns and weight gain in physically active and sedentary pregnant women in Tshwane, South Africa. African J Phys Heal Educ Recreat Danc. 2012;18(Supplement 1):132-43 Available from: https:// journals.co.za/content/ajpherd/18/sup-1/EJC119814.

31. Hjorth MF, Kloster S, Girma T, Faurholt-Jepsen D, Andersen G, Kæstel P, et al. Level and intensity of objectively assessed physical activity among pregnant women from urban Ethiopia. BMC Pregnancy Childbirth. 2012;12(1):154.

32. Ababa A. Federal Democratic Republic of Ethiopia Central Statistical Agency Population Projection of Ethiopia for All Regions At Wereda Level from 2014-2017. 2017;(August 2013).

33. Demographic E. Health survey central statistical agency Addis Ababa, Ethiopia; 2016.

34. Ababa A. Federal Ministry of Health, Ethiopia (2009), Health and Healthrelated indicators. Addis Ababa, Ethiopia; 2017

35. Chasan-Taber L, Schmidt MD, Roberts DE, Hosmer D, Markenson G, Freedson PS. Development and validation of a pregnancy physical activity questionnaire. Med Sci Sports Exerc. 2004;36(10):1750-60.

36. Hosmer DW, Lemeshow S. Applied Logistic Regression. 2nd ed. New York: Wiley; 2000.

37. Tran A, Gelaye B, Girma B, Lemma S, Berhane Y, Bekele T, WM KA. Prevalence of metabolic syndrome among working adults in Ethiopia. Int J Hypertens. 2011;26:193719.

38. Smith KM, Campbell CG. Physical Activity during Pregnancy: Impact of Applying Different Physical Activity Guidelines. J Pregnancy. 2013;2013:8. Available from:. https://doi.org/10.1155/2013/165617

\section{Publisher's Note}

Springer Nature remains neutral with regard to jurisdictional claims in published maps and institutional affiliations. 